\title{
A simple method to estimate the significance level of the catch probability in the catch removal method in river fish populations
}

\author{
R. Bravo*, M.C. Soriguer, N. Villar, J.A. Hernando \\ Facultad de Ciencias del Mar. Departamento de Biología Animal, \\ Biología Vegetal y Ecología. Apartado 40-11510 Puerto Real, Cádiz, Spain
}

Received 26 November 1998; received in revised form 21 June 1999; accepted 14 July 1999

\begin{abstract}
This work presents a method for estimating the significance level of the capture probability when the capture removal method is used in riverine fish populations. The method is based on adjustment of the linear relationship between capture probability and an index of capture efficacy. With this method the population size, the statistic $\chi^{2}$ and the significance level of the capture probability can be estimated. This is a simple technique which can be applied in the field at the time of sampling. It does not require the use of computers and can determine in situ whether the catch is valid to calculate the population density. (C) 1999 Elsevier Science B.V. All rights reserved.
\end{abstract}

Keywords: Catch removal method; Fish population; Maximum likelihood; Probability

\section{Introduction}

Estimation of the abundance of riverine fish populations is an important step in any study of population dynamics. The methodology used for this purpose is well established and two kinds of techniques are generally used: the capture-mark-recapture method and the catch removal method.

The Maximum Likelihood Method, which belongs to the latter group, gives the most accurate estimates and has the greatest statistical rigor (Cowx, 1983).

\footnotetext{
* Corresponding author. Tel.: +34-56-470884; fax: +34-56470811

E-mail address: ramon.bravo@uca.es (R. Bravo)
}

These models were initially developed by Moran (1951), were simplified by Zippin $(1956,1958)$ and adapted by Platts et al. (1983) giving rise to a mathematical formula simple to use in computer programmes.

In addition to estimating the density and standard error, the method also calculates the degree of fit to the model, i.e. the catch efficiency or capture probability $(p)$. This parameter estimates the relationship between the number of fish captured and the number not captured. It corresponds to the probability that a member of the population will be captured.

This work presents a method to determine the significance level of the capture probability which can be used in the field at the time of sampling, 
without the use of computers, applied to long-term studies.

\section{Materials and methods}

The Palancar Stream is a small tributary of the Guadalquivir River situated in the Parque Natural de las Sierras Subbéticas de Córdoba, in the south of the Iberian Peninsula between the co-ordinates $37^{\circ} 28^{\prime} 33^{\prime \prime}-37^{\circ} 27^{\prime} 39^{\prime \prime} \mathrm{N}$ and $4^{\circ} 18^{\prime} 10^{\prime \prime}-4^{\circ} 17^{\prime} 15^{\prime \prime} \mathrm{W}$.

Quantitative samples were taken every season over two years, from summer 1994 to summer 1995 (five samples) and from summer 1996 to summer 1997 (five samples).

The catch per unit of effort method was used. A stop net $(2.5 \mathrm{~mm}$ diam. mesh) was placed at the downstream limit of each site. Three people waded upstream and electrofished with anode-dipnets for a constant time (45 min).

The Zippin maximum-likelihood method for three catches (Zippin, 1956, 1958) was used for estimating population size $(N)$, catch efficiency $(p)$ and $95 \% \mathrm{CL}$ (Mahon, 1980), simplified by Platts et al. (1983). The FSAS program was used for the statistical analysis (Saila et al., 1988).

In order to test the fit of the model, $\chi^{2}$ was calculated using the null hypothesis that the capture probability was constant over the sampling period (Platts et al., 1983). When the adjustment was significant the model was considered to give a good estimate of population size.

The following index of catch efficiency, different to the catch probability, is defined:

$\epsilon=\frac{C_{1} \cdot 100}{C}$,

where $C_{1}$ is the number of fish caught in the first removal and $C$ the total catch.

The method we propose consists of adjusting the linear relationship between the capture probability $(p)$ and the catch efficiency $\epsilon$. In order to do this we carried out a significant number of samplings. Other simple solutions have been proposed for calculating the probability of capture by means of generic curves (Seber, 1982), but in this study we calculate specific curves for each population.

With this ratio the index $\epsilon$ and the capture probability are calculated for a new sampling. Applying the formula of Platts et al. (1983) the population size is calculated from the equation:

$N=C+\frac{C}{k \cdot P}-\frac{S}{k}$,

where $k$ is the number of removals made during the sampling (in this work $k=3$ ) and $S$ is equivalent to:

$S=\sum_{i=1}^{k} i \cdot C_{i}$,

where $C_{i}$ is the number of individuals caught on occasion $i$. The significance of the capture probability $\left(\chi^{2}\right)$ can be easily calculated from the equation:

$\chi^{2}=\sum_{i=1}^{k} \frac{\left(C_{i}-E_{i}\right)^{2}}{E_{i}}$

where $E_{i}=N \cdot p(p-1)^{i-1}$.

The statistic obtained should be compared to the tabulated value of $\chi^{2}$ with $k-1$ degrees of freedom. In this work, in which three removals were carried out, the capture probability is constant when $\chi^{2}<5.991$ and $\alpha>0.05$.

\section{Results and discussion}

The fish community of the Palancar Stream is comprised of four species: Leuciscus pyrenaicus (Günther, 1868), Barbus sclateri (Günther, 1868), Cobitis paludica (De Buen, 1930) and Micropterus salmoides (Lacépède, 1802). The latter was only caught in the last sampling.

The catches of each population and the linear relationships are shown in Tables 1 and 2, respectively. The adjustment to fit the straight line was significant in all cases $(* * * P<0.001)$, permitting good estimates of $p$ as a function of $\epsilon$.

When $\alpha<0.05$ the capture probability is not constant and the estimate of population size is poor. In this case the sampling should continue, another removal should be carried out and the value of $\epsilon$ should be calculated again to determine whether the sampling is valid, and so on. The importance of applying these equations for each population in the 
Table 1

Catches made in each successive sampling $\left(C_{n}\right)$ and the total catch $(C)^{\mathrm{a}}$

\begin{tabular}{|c|c|c|c|c|c|c|c|c|c|c|}
\hline Sampling date & $C_{1}$ & $C_{2}$ & $C_{3}$ & $C$ & $N$ & $s_{n-1}$ & $\epsilon$ & $p$ & $\chi^{2}$ & $\alpha$ \\
\hline \multicolumn{11}{|l|}{ B. sclateri } \\
\hline 220794 & 188 & 74 & 41 & 303 & 331 & 9.53 & 62.04 & 0.558 & 1.445 & 0.485 \\
\hline 261194 & 108 & 35 & 23 & 166 & 178 & 5.91 & 65.06 & 0.587 & 3.159 & 0.206 \\
\hline 180395 & 11 & 62 & 50 & 223 & 306 & 31.4 & 49.77 & 0.352 & 1.475 & 0.478 \\
\hline 210595 & 145 & 62 & 23 & 230 & 245 & 6.38 & 63.04 & 0.601 & 0.219 & 0.896 \\
\hline 200795 & 177 & 89 & 69 & 335 & 427 & 27.5 & 52.83 & 0.400 & 2.916 & 0.232 \\
\hline 060896 & 25 & 11 & 11 & 47 & 59 & 9.87 & 53.19 & 0.405 & 1.547 & 0.461 \\
\hline 301196 & 45 & 24 & 22 & 91 & 127 & 21.7 & 49.45 & 0.341 & 1.331 & 0.514 \\
\hline 220297 & 53 & 51 & 22 & 126 & 181 & 28.5 & 42.06 & 0.326 & 4.643 & 0.098 \\
\hline 240597 & 36 & 18 & 4 & 58 & 60 & 2.42 & 62.07 & 0.644 & 1.669 & 0.431 \\
\hline 210797 & 83 & 19 & 9 & 111 & 113 & 2.01 & 74.77 & 0.721 & 1.753 & 0.416 \\
\hline \multicolumn{11}{|l|}{ L. pyrenaicus } \\
\hline 220794 & 232 & 160 & 58 & 450 & 532 & 21.0 & 51.55 & 0.463 & 2.060 & 0.360 \\
\hline 261194 & 89 & 66 & 62 & 217 & 484 & 152.3 & 41.01 & 0.180 & 0.654 & 0.721 \\
\hline 180395 & 91 & 78 & 62 & 231 & 513 & 155.3 & 39.39 & 0.181 & 0.087 & 0.957 \\
\hline 210595 & 114 & 85 & 56 & 255 & 387 & 49.8 & 44.70 & 0.301 & 0.224 & 0.890 \\
\hline 200795 & 157 & 118 & 94 & 369 & 672 & 110.1 & 42.55 & 0.233 & 0.076 & 0.962 \\
\hline 060896 & 155 & 97 & 86 & 338 & 549 & 72.83 & 45.85 & 0.273 & 2.070 & 0.355 \\
\hline 301196 & 180 & 101 & 80 & 361 & 495 & 39.75 & 47.24 & 0.352 & 2.085 & 0.352 \\
\hline 220297 & 124 & 78 & 33 & 235 & 277 & 14.94 & 52.76 & 0.465 & 1.785 & 0.409 \\
\hline 240597 & 66 & 52 & 48 & 166 & 402 & 165.4 & 39.76 & 0.163 & 0.247 & 0.883 \\
\hline 210797 & 147 & 83 & 27 & 257 & 284 & 9.74 & 57.2 & 0.541 & 3.387 & 0.184 \\
\hline \multicolumn{11}{|l|}{ C. paludica } \\
\hline 220794 & 5 & 5 & 5 & 15 & 41 & 70 & 33.33 & 0.139 & 0.232 & 0.890 \\
\hline 261194 & 13 & 5 & 4 & 22 & 24 & 2.9 & 59 & 0.537 & 0.716 & 0.690 \\
\hline 180395 & 31 & 14 & 9 & 54 & 61 & 5.58 & 57.41 & 0.505 & 0.384 & 0.825 \\
\hline 210595 & 9 & 5 & 5 & 19 & 25 & 8.22 & 47.36 & 0.365 & 0.594 & 0.740 \\
\hline 200795 & 13 & 11 & 9 & 33 & 62 & 36.88 & 56.52 & 0.221 & 0.105 & 0.948 \\
\hline 060896 & 7 & 1 & 2 & 10 & 10 & 0.85 & 70 & 0.667 & 2.844 & 0.241 \\
\hline 301196 & 1 & 4 & 9 & 14 & 14 & 8.33 & 7.14 & 0.012 & 7.252 & 0.026 \\
\hline 220297 & 10 & 17 & 7 & 34 & 75 & 59.22 & 29.41 & 0.181 & 4.545 & 0.100 \\
\hline 240597 & 17 & 3 & 6 & 26 & 28 & 2.85 & 65.38 & 0.553 & 5.112 & 0.077 \\
\hline 210797 & 23 & 18 & 2 & 43 & 43 & 3.10 & 53.49 & 0.581 & 6.200 & 0.045 \\
\hline
\end{tabular}

${ }^{a} N$ is the population size calculated, $s_{n-1}$ represents the standard deviation. $p$ is the capture probability, $\epsilon$ the catch efficiency, $\chi^{2}$ the test of significance and $\alpha$ the significance level of the Zippin method.

Table 2

Regression lines between the capture probability $(p)$ and the efficiency index $(\epsilon)$ ( $r$ is the coefficient of regression)

\begin{tabular}{llll}
\hline Ecuation & B. sclateri & L. pyrenaicus & C. paludica \\
\hline$p=a+b \cdot \epsilon(r)$ & $p=-0.333+0.0143 \epsilon(r=0.960)$ & $p=-0.714+0.022 \epsilon(r=0.988)$ & $p=-0.1167+0.1028 \epsilon(r=0.883)$
\end{tabular}

field can not be undermined, since if these calculations are made a posteriori in the laboratory and an $\alpha<0.05$ is obtained, it will be too late to rectify the results.

Obviously, these equations can only be calculated in long-term studies since they are intrinsic for each population. The variable capture probability is not only dependent on the characteristics and habits of fish populations but also on factors related to the design and implementation of the sampling and on the physical, chemical and environmental characteristics of the habitat (Lobón-Cerviá, 1991). 


\section{Acknowledgements}

This study was funded by the DGICYT (Spain), project no. PB92-0093 and by a grant from the Fundación Caja de Madrid. The authors would also like to thank members of the research team of Fish Population Dynamics (RNM 243, Cadiz University) for their help in the field work.

\section{References}

Cowx, I.G., 1983. Review of the methods for estimating fish population size from survey removal data. Fish. Mgmt. 14(2), $67-82$.

Lobón-Cerviá, J., 1991. Dinámica de Poblaciones de Peces en Ríos, Pesca Pesca Electrica y Métodos de Capturas Sucesivas en la Estima de Abundancias. Monografías del Museo Nacional de Ciencias Naturales, No. 3, Madrid, CSIC.

Mahon, R., 1980. Accuracy of catch-effort methods for estimating fish density and biomass in streams. Envir. Biol. Fish. 5, 343360.

Moran, P.A.P., 1951. A mathematical theory of animal trapping. Biometrika. 38, 307-311.

Platts, W.S., Megahan, W.F., Minshall, G.W., 1983. Methods for evaluating stream, riparian, and biotic conditions. Gen. Tech. Rep. INT-138. Odgen, V. T. USDA Forest Service, Intermountain and Range Experiment Station.

Saila, S.B., Recksick, C.W., Prager, M.H., 1988. Basic fishery science programs. A compendium of microcomputer programs and manual of operation. Elsevier, Amsterdam.

Seber, G.A.F., 1982. The Estimation of Animal Abundance and Related Parameters. Charles Griffin, London.

Zippin, C., 1956. An evaluation of the removal method of estimating animal populations. Biometrics 12, 163-189.

Zippin, C., 1958. The removal method population and estimation. J. Wild. Mgmt. 22, 82-90. 